\title{
CONCENTRATIONS OF LEAD (Pb) IN ROAD DUST IN BANDAR SERI BEGAWAN, BRUNEI DARUSSALAM
}

\author{
Shahrizal Emran, K. Rodney Fernando and Miroslav Radojevic \\ Department of Chemistry \\ University of Brunei Darussalam \\ Brunei Darussalam
}

\begin{abstract}
A first-ever survey of lead (Pb) in road dust in Bandar Seri Begawan (B.S.B.), the capital of Brunei Darussalam, was carried out in 1996, three years after the introduction of unleaded petrol. The concentration of $\mathrm{Pb}$ at 114 sites varied between 12 and $544 \mu \mathrm{g} / \mathrm{g}$ (mean: $125 \mu \mathrm{g} / \mathrm{g}$; standard deviation: $103 \mu \mathrm{g} / \mathrm{g}$ ). There was a significant correlation $(\mathrm{r}=0.546)$ between lead in road dust and traffic volume at 17 sites for which traffic counts were available. An assessment of the potential hazard posed to children was made. It is concluded that concentration levels of $\mathrm{Pb}$ in road dust in B.S.B. are considerably lower than levels found in London and Hong Kong, and they do not pose a major public health hazard.
\end{abstract}

\section{INTRODUCTION}

The major source of lead $(\mathrm{Pb})$ in the environment of Brunei Darussalam is the use of tetraalkyllead as a petrol additive. In order to protect the public, measures were taken to reduce emissions of $\mathrm{Pb}$. In 1992, the $\mathrm{Pb}$ content of petrol was reduced from 400 to 150 $\mathrm{mg} / \mathrm{L}$, and in January 1993 unleaded petrol was introduced for the first time. Unleaded petrol assumed a $50 \%$ market share within two years of its introduction.

Earlier studies of $\mathrm{Pb}$ in the environment of Brunei, involving mainly analysis of surface waters, revealed low levels of $\mathrm{Pb}$ contamination ${ }^{1}$. As the major fate of $\mathrm{Pb}$ emitted from motor vehicles is deposition at the roadside it was decided that a detailed survey of $\mathrm{Pb}$ in road dust of Bandar Seri Begawan (B.S.B.) was required. The survey was carried out during 1996.

Bandar Seri Begawan (B.S.B.) is the capital of Brunei Darussalam. It is the major urban area in the country with a population of $c a .50,000$. Per capita car ownership in Brunei is among the highest in the world; it exceeds 0.3. The number of registered motor vehicles in the whole country was $c a .150,000$ in 1996, the majority of these being in the B.S.B. area. 


\section{MATERIALS AND METHODS}

Road dust samples were collected at 114 sites throughout the B.S.B. area covering a variety of roads from busy town centre streets to quiet, suburban roads in residential areas. Samples were collected after several days of dry weather as rain could bring considerable reduction in the level of lead in road dust. Approximately $5 \mathrm{~g}$ of dust were collected from the roadside using a dustpan and brush, and stored in a polyethylene bag. Samples were sieved, dried in an oven at $110^{\circ} \mathrm{C}$ for one hour and cooled in a desiccator. Approximately $2 \mathrm{~g}$ of dried dust were accurately weighed and placed inside a 100 millilitre (mL) beaker together with $50 \mathrm{~mL}$ of $2 \mathrm{M}$ nitric acid. Boiling chips were added and a watch glass was placed on the beaker. The mixture was heated on a hotplate until the volume was reduced to about $10 \mathrm{~mL}$ and then cooled. The mixture was then filtered through a Whatman No. 91 filter paper into a $25 \mathrm{~mL}$ volumetric flask, and the beaker and paper were washed with small volumes of $1 \mathrm{M}$ nitric acid which were also added to the flask. The flask was made up to the mark and the extract was analysed by means of flame atomic absorption spectrophotometry (AAS) using a Philips PU9100 Atomic Absorption Spectrophotometer in an air/acetylene flame at a wavelength of $217 \mathrm{~nm}$. Eight standards covering the range from 1 to $25 \mu \mathrm{g} / \mathrm{mL}$ were prepared by dilution from a $1000 \mu \mathrm{g} / \mathrm{mL}$ Pb stock solution and analysed to give a calibration curve.

\section{RESULTS AND DISCUSSION}

\subsection{Level of contamination}

The concentration of $\mathrm{Pb}$ in dry dust samples varied between 12 and $544 \mu \mathrm{g} / \mathrm{g}$. The mean concentration was $125 \mu \mathrm{g} / \mathrm{g}$ and the standard deviation was $103 \mu \mathrm{g} / \mathrm{g}$. Concentrations of $\mathrm{Pb}$ in B.S.B. are considerably lower than concentrations reported for other cities; for example, concentrations of $\mathrm{Pb}$ in road dust in London in the early $1990 \mathrm{~s}$ varied between 400 and several thousand $\mu \mathrm{g} / \mathrm{g}$ according to Evans et ${ }^{2}$. There are no international standards for $\mathrm{Pb}$ in road dust but the Greater London Council recommended a guideline value of $500 \mu \mathrm{g} / \mathrm{g}$ and a similar guideline has been proposed in the U.S. ${ }^{3}$ Since concentrations of $\mathrm{Pb}$ in road dust of B.S.B. rarely exceed this value it can be concluded that $\mathrm{Pb}$ pollution is not a major environmental problem in Brunei Darussalam.

\subsection{Distribution of $\mathrm{Pb}$ in B.S.B.}

The spatial distribution of relative $\mathrm{Pb}$ concentrations in road dust and traffic volume around the city is illustrated in Figure 1 based on measurements at representative sites. Highest concentrations were recorded in the downtown and commercial districts with higher traffic, whereas lower concentrations were observed in suburban and residential areas. 


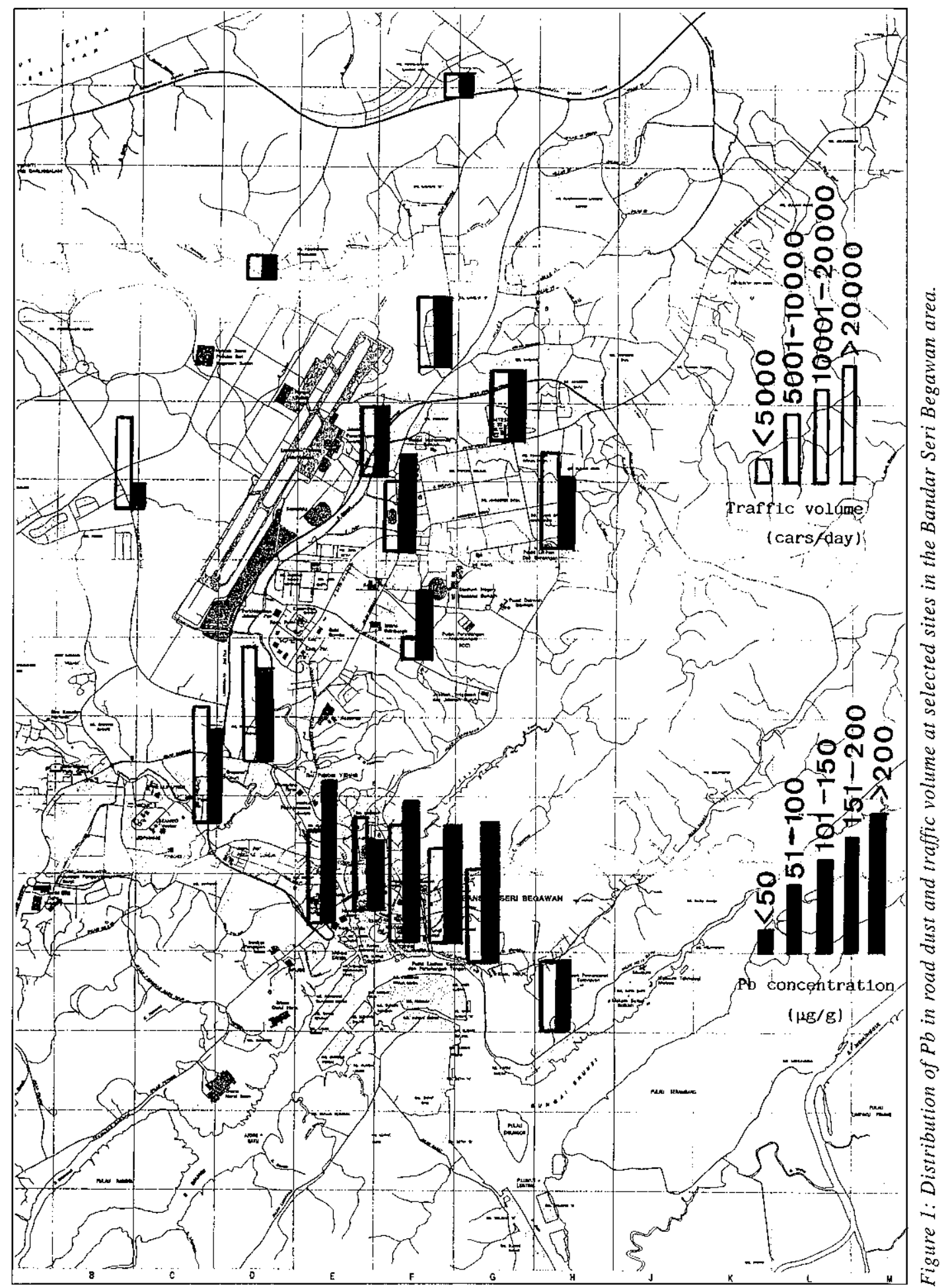




\subsection{Intrasite variability}

Intrasite variability was studied by taking five roadside dust samples at $1 \mathrm{~m}$ intervals. These tests showed coefficients of variation of $c a .50 \%$ for $\mathrm{Pb}$ in road dust. High variability has also been noted in other studies. For example, coefficients of variation between $17 \%$ and $45 \%$ were reported for street dust in London ${ }^{2}$. High variability is to be expected since $\mathrm{Pb}$ in roadside dust depends on many factors including traffic volume, driving mode, street-cleaning practices, non-traffic sources (e.g. print works), meteorological conditions (e.g. rainfall, wind speed), etc.

\subsection{Relationship between $\mathrm{Pb}$ concentration and traffic volume}

Traffic counts were available for 17 sites in B.S.B. Traffic counts were made one year prior to the lead survey. The total number of registered motor vehicles in the whole country increased by $26 \%$ during the period 1995-1996. Although the amount of traffic in the city had increased, there had been no major change in the relative traffic volumes at each site by the time the survey was carried out. Concentrations of $\mathrm{Pb}$ measured in several samples collected at these sites were averaged (Table 1) and correlated with the traffic volume. A plot of $\mathrm{Pb}$ versus traffic volume is shown in Figure 2. The value of Pearson's correlation coefficient was 0.546 indicating a significant relationship between $\mathrm{Pb}$ in road dust and traffic volume $(P>0.05)$. Although this relationship is to be expected, as vehicular traffic is the main source of $\mathrm{Pb}$ in urban environments, previous studies at other locations have failed to find any significant relationship between $\mathrm{Pb}$ in road dust and traffic volume. For example, studies in Hong Kong observed a significant relationship between traffic volume and $\mathrm{Pb}$ in roadside soil and grass ${ }^{4}$, but failed to observe a significant correlation with road dust ${ }^{5}$.

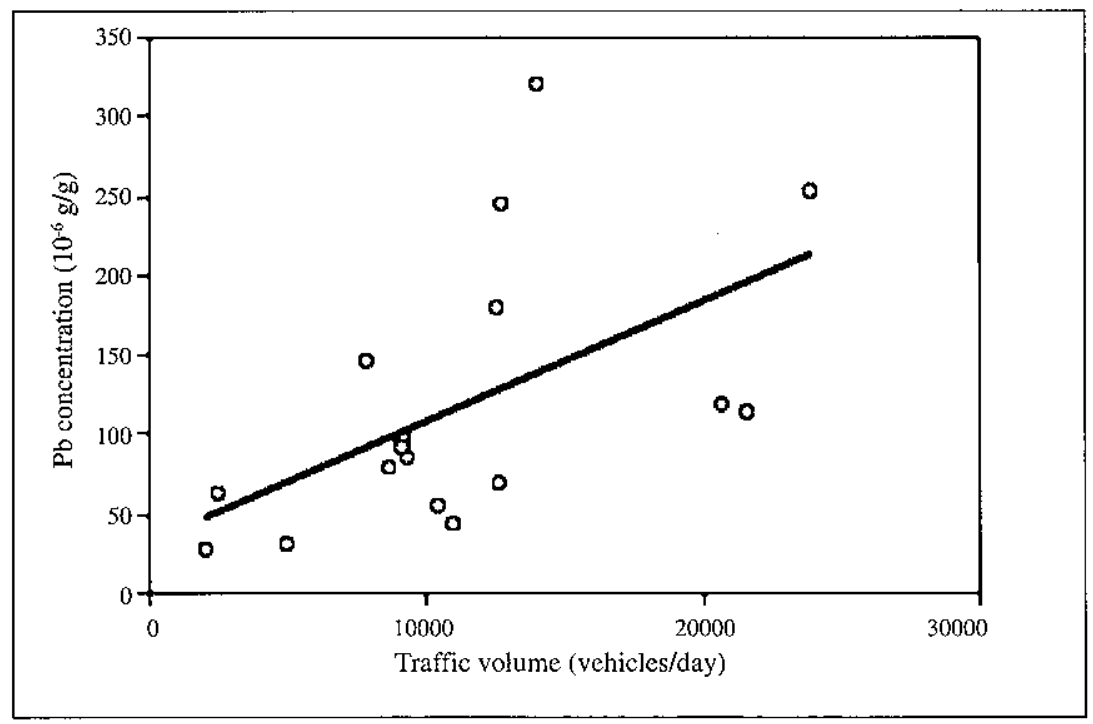

Figure 2: Correlation chart of $P b$ in road dust versus traffic volume $(r=0.546)$. 
Table 1: Traffic volume, mean $\mathrm{Pb}$ in road dust, $\mathrm{Pb}$ concentration range, and contribution to $\mathrm{Pb}$ in blood of children at several sites in Bandar Seri Begawan.

\begin{tabular}{|c|c|c|c|c|c|}
\hline Site & $\begin{array}{c}\text { Traffic } \\
\text { volume } \\
\text { (cars/day) }\end{array}$ & $\begin{array}{l}\text { Mean Pb } \\
\text { road dust } \\
(\mu \mathrm{g} / \mathrm{g})\end{array}$ & $\begin{array}{c}\text { Pb concentration } \\
\text { range } \\
(\mu \mathrm{g} / \mathrm{g})\end{array}$ & $\mathbf{N}$ & $\begin{array}{c}\text { Contribution } \\
\text { to } \mathrm{Pb} \text { in blood } \\
(\mu \mathrm{g} / \mathrm{DL})\end{array}$ \\
\hline Jln. Sultan & 23910 & 252 & $109-398$ & 6 & 1.81 \\
\hline Jln. Residency & 12754 & 245 & $155-278$ & 6 & 1.76 \\
\hline Jln. Kota Batu & 9300 & 84 & $54-108$ & 3 & 0.61 \\
\hline Jln. Stoney & 12685 & 68 & $45-90$ & 2 & 0.49 \\
\hline Jln. Kebangsaan & 10464 & 55 & $54-56$ & 3 & 0.39 \\
\hline Jln. Muara & 9176 & 97 & $45-180$ & 3 & 0.70 \\
\hline Jln. Berakas & 8718 & 79 & $42-138$ & 5 & 0.57 \\
\hline Jln. Gadong & 21559 & 113 & $48-229$ & 13 & 0.81 \\
\hline Jln. Tutong & 14068 & 319 & $69-544$ & 3 & 2.30 \\
\hline Jln. Menteri Besar & 2538 & 63 & $49-78$ & 2 & 0.46 \\
\hline SHB Highway & 20670 & 118 & $22-294$ & 12 & 0.85 \\
\hline Tungku Link & 10984 & 43 & $12-66$ & 5 & 0.31 \\
\hline Coastal Highway & 4984 & 30 & $13-90$ & 7 & 0.22 \\
\hline North Rimba Road & 2055 & 27 & $14-50$ & 4 & 0.20 \\
\hline $\begin{array}{l}\text { Jln. Sungai } \\
\text { Kianggeh }\end{array}$ & 12532 & 179 & $115-211$ & 3 & 1.29 \\
\hline $\begin{array}{l}\text { Berakas } \\
\text { Roundabout }\end{array}$ & $\begin{array}{c}7874 \\
\text { (from B.S.B.) } \\
\end{array}$ & 146 & $23-322$ & 4 & 1.04 \\
\hline $\begin{array}{l}\text { Berakas } \\
\text { Roundabout }\end{array}$ & $\begin{array}{c}9148 \\
\text { (from airport) }\end{array}$ & 91 & $\mathrm{NA}$ & 1 & 0.65 \\
\hline
\end{tabular}

$N$ refers to the number of sampling sites along a particular road. NA denotes not available.

\subsection{Degree of hazard posed to children}

As many of the sites surveyed in this study are in close proximity to schools, kindergartens and public housing, we decided to estimate the contribution of $\mathrm{Pb}$ in dust to blood lead levels in children. The contribution of road dust to the blood levels of $\mathrm{Pb}$ in children was estimated using the United States Environmental Protection Agency (US EPA) biokinetic uptake model as described by Evans $e t a l^{2}$. The main assumptions of this model are that children in the 0 to 6 year range ingest some $60 \mathrm{mg}$ of dust per day and that $30 \%$ of the ingested $\mathrm{Pb}$ is absorbable. The amount of absorbable $\mathrm{Pb}$, in $\mu \mathrm{g}$, is multiplied by 0.4 to convert to $\mu \mathrm{g}$ of $\mathrm{Pb}$ per decilitre (dL) of blood. In the absence of data on indoor $\mathrm{Pb}$ concentrations, we assumed a ratio of indoor to outdoor $\mathrm{Pb}$ in dust of $1: 1$. Contributions to blood $\mathrm{Pb}$ in B.S.B. at 17 road sites covering a range of traffic conditions are given in 
Table 1 . Contributions to $\mathrm{Pb}$ in blood of children vary between 0.2 and $2.3 \mu \mathrm{g} / \mathrm{dL}$. In a similar study conducted in London ${ }^{2}$, contributions of road dust to blood $\mathrm{Pb}$ varied from 3.6 to $20.3 \mu \mathrm{g} / \mathrm{dL}$, considerably higher than in B.S.B.

\section{CONCLUSIONS AND RECOMMENDATIONS}

A detailed survey of lead $(\mathrm{Pb})$ in road dust of Bandar Seri Begawan was carried out. The concentration of $\mathrm{Pb}$ varied between 12 and $544 \mu \mathrm{g} / \mathrm{g}$ in 114 samples collected at various sites throughout the city. A significant correlation was observed between $\mathrm{Pb}$ in road dust and traffic volume at 17 sites for which traffic counts were available, indicating that vehicle emissions were the dominant source of $\mathrm{Pb}$. Concentrations of $\mathrm{Pb}$ in road dust of Bandar Seri Begawan are considerably lower than concentrations reported for London and Hong Kong, and they are well below recommended guideline values. The contribution of road dust to blood levels of $\mathrm{Pb}$ in children in Bandar Seri Begawan was estimated to be considerably lower than that in a major urban area such as London, and it can be concluded that $\mathrm{Pb}$ is not a significant environmental hazard in Brunei Darussalam.

This study should be extended to include other important urban pollutants in dust ( $\mathrm{Zn}$ and $\mathrm{Cd})$ and in the air $\left(\mathrm{NO}_{\mathrm{x}}, \mathrm{O}_{3}\right.$ and $\left.\mathrm{CO}\right)$.

\section{ACKNOWLEDGEMENT}

We would like to thank the Public Works Department for providing the traffic counts.

\section{REFERENCES}

1. Radojevic M., Fernando K.R. and Lim L.H. Research into environmental pollution at the University of Brunei Darussalam. In: Proceedings of the International Symposium on Climate and Life in the Asia Pacific, 10-13 April 1995 (ed. Sirinanda K.U.) University of Brunei Darussalam, 1995, pp. 30-39.

2. Evans E., Ma M., Kingston L. and Laharne S., The speciation pattern of lead in street dusts and soils in the vicinity of two London schools. Environment International, 1992, 18, 153-162.

3. Radojevic M. and Bashkin V.N., Practical Environmental Analysis, Royal Society of Chemistry, Cambridge, 1999, p.363.

4. Ho Y.B. and Tai K.M., Elevated levels of lead and other metals in roadside soil and grass and their use to monitor aerial metal depositions in Hong Kong. Environmental Pollution, 1988, 49, 37-51.

5. Ho Y.B., Lead contamination in street dust in Hong Kong. Bull. Environ. Contam. Toxicol., 1979, 21, 639-642. 